\title{
Use of phage antibodies to distinguish closely related species of protozoan parasites
}

\author{
Timothy Paget ${ }^{\mathrm{a}, *}$, Naveed Khan ${ }^{\mathrm{a}}$, \\ Graham Temple ${ }^{\mathrm{c}}$, Victoria Hough ${ }^{\mathrm{b}}$ and \\ John Greenman ${ }^{\mathrm{b}}$ \\ ${ }^{\mathrm{a}}$ Department of Biological Sciences, Hardy Building, \\ and ${ }^{\mathrm{b}}$ Academic Surgical Unit, Wolfson Building, The \\ University of Hull, Hull HU6 7RX, UK \\ ${ }^{\mathrm{c}} \mathrm{PHL}$, Hull Royal Infirmary, Hull HU3 2JZ, UK
}

Acanthamoeba are typically identified in the laboratory using culture and microscopic observation. In this paper we describe the isolation and specificity of antibody fragments that can be used for the identification of Acanthamoeba. A phage library expressing a large repertoire (approx. $5 \times 10^{9}$ ) of antibody fragments was used to generate two libraries one enriched for bacteriophage that exhibit genus specific binding and the other containing bacteriophage that bind specifically to pathogenic Acanthamoeba. Individual clones were isolated on the basis of binding by ELISA, and then flow cytometry and immunofluorescence were used for further characterisation. Four monoclonal antibodies were isolated, specific for Acanthamoeba at the generic level with clone HPPG6 exhibiting the highest level of binding. Furthermore clone HPPG55 was specific for pathogenic species of Acanthamoeba.

\section{Introduction}

Methods used for the detection of parasites have undergone a rapid change over the past ten years; however morphology is still the single most useful diagnostic character. Species determination of non-culturable or morphologically similar organisms relies on the use of PCR based technology or monoclonal antibodies $(\mathrm{mAb})$, the latter typically being used in either an ELISA format or for fluorescence microscopy. Both

${ }^{*}$ Correspondence to: Dr. Timothy Paget, Department of Biological Sciences, Hardy Building, The University of Hull, Hull HU6 7RX, UK. Tel.: +44 1482 465506; Fax: +44 1482 466996; E-mail: T.A.Paget@biosci.hull.ac.uk. methodologies are used in laboratories for the detection and identification of parasites such as Plasmodium, Leishmania and Cryptosporidium, but each has some disadvantages. mAb often show cross reactivity within a genus or, in extreme cases, between different genus groups (as seen with cryptosporidium) [8]; PCR is more reliable although the cost is prohibitively high when small numbers of assays are performed annually. For those organisms that are difficult to culture or are nonculturable in vitro, identification of phenotypic characteristics such as drug resistance or pathogenicity are difficult using current technology (see Freeman "Images and antibodies - the potential of bacteriophage antibody display to clinical microbiology"). A good example of this problem is seen with the identification of Acanthamoeba infections in man.

Acanthamoeba is a free-living opportunistic protozoan parasite of man, which can cause a fatal meningoencephalitis disease, but is more commonly associated with eye infections (Acanthamoeba keratitis). The number of cases annually in the UK of Acanthamoeba keratitis is approximately 150. Acanthamoeba keratitis is typically diagnosed after viral and bacterial causes have been eliminated [1,5] and, as a result, there is a significant delay before appropriate treatment is administered. Because of the severity of Acanthamoeba keratitis a significant loss of visual acuity is common and in many cases total loss of sight in the eye occurs [4, 6]. Although commonly isolated, only a limited number of Acanthamoeba are pathogenic thus, the development of a rapid, simple detection method for such strains is important $[2,17]$. Current methods of detection involve culture and microscopic identification [16]. These methods are time consuming, laborious and open to error.

This paper outlines our approach for generating antibody fragments that can be used to differentiate pathogenic Acanthamoeba either by immunofluorescence microscopy or flow cytometry. 
Table 1

Acanthamoeba species used in this study. The pathogenicity of the strains was determined by observing cytopathic effects and is taken from Khan et al. [10]. The numbers of Acanthapodia per cell were determined from SEM pictures and the individual values expressed are an average calculated from counts on 25 cells

\begin{tabular}{lllcr}
\hline No & \multicolumn{1}{c}{ Species } & \multicolumn{1}{c}{ Strain } & $\begin{array}{c}\text { Pathogenically } \\
\text { tested by CPE assays }\end{array}$ & $\begin{array}{c}\text { Average no. of } \\
\text { Acanthapodia per cell }\end{array}$ \\
\hline 1 & A. astronyxis (Sp1) & CCAP 1534/1 & Non-pathogen & 2 \\
2 & A. royreba (Sp2) & CCAP 1501/7 & Non-pathogen & 105 \\
3 & A. palestinensis (Sp3) & CCAP 1547/1 & Non-pathogen & 15 \\
4 & A. polyphaga (Sp4) & CCAP 1501/3C & Non-pathogen & 14 \\
9 & A. griffini (Sp5) & CCAP 1501/4 & Non-pathogen & 7 \\
6 & Acanthamoeba sp. (Sp6) & & Pathogen & 148 \\
7 & Acanthamoeba sp. (Sp7) & & Pathogen & 124 \\
5 & A. castellanii $(\mathrm{Sp} 8)$ & ATCC 30234 & Pathogen & 180 \\
8 & A. polyphaga (Sp9) & ATCC 30871 & Pathogen & 166 \\
\hline
\end{tabular}

\section{Material and methods}

\subsection{Cell cultures}

Pathogenic and non-pathogenic Acanthamoeba species were either obtained from CCAP (Culture Collection of Algae and Protozoa) or from Dr. S. Kilvington (Leicester PHL). All Acanthamoeba spp. were maintained as described by Khan et al. [10]. The Acanthamoeba species used in this study are shown in Table 1. For all experiments, Acanthamoeba were harvested by centrifugation at $800 \times \mathrm{g}$ for $8 \mathrm{~min}$ and resuspended in PAS (Page's amoeba saline) [10]. Centrifugation was repeated a further three times. Cells used for isolating antibody fragments, ELISA and FACS analysis were fixed in 50\% (v/v) methanol in PAS. After fixation, cells were washed three times with PAS as described above. Organisms used for immunofluorescence microscopy were harvested and placed directly onto slides prior to fixation.

\subsection{Scanning Electron Microscopy (SEM)}

Cells were prepared for SEM using the following protocol: coverslips were cleaned by soaking in $100 \%$ ethanol, wiped with lint free paper and air dried for at least $1 \mathrm{~h}$. A drop of $0.1 \%(\mathrm{w} / \mathrm{v})$ poly-1-lysine was placed on each coverslip, dried overnight, and then rinsed in distilled water. Acanthamoeba in PAS were placed on the coverslip and left for 5-10 min to allow cells to adhere. The coverslips were washed with $2.5 \%$ (v/v) gluteraldehyde at $4{ }^{\circ} \mathrm{C}$, and left overnight. The following day, they were washed again with ice cold PAS and left overnight. Samples were finally washed with distilled water at room temperature and left for $30 \mathrm{~min}$. Coverslips were then dehydrated in a series of acetone and water mixtures from $30 \%$ acetone in water to $100 \%$ acetone. Samples were finally heated at $36^{\circ} \mathrm{C}$, mounted, and observed under SEM.

\subsection{Bacteriophage display library}

The semi-synthetic ScFv library no. 1 (Nissim Library) was obtained from G. Winter (Centre for Protein Engineering, Medical Research Council Centre, Cambridge, United Kingdom) [14].

\subsection{Preparation of bacteriophage particles}

For bacteriophage preparation, the library stock or individual phage clones were added to a culture of Escherichia coli (TG1) grown in $2 \times \mathrm{TY}(0.8 \%(\mathrm{w} / \mathrm{v})$ $\mathrm{NaCl}, 1.6 \%(\mathrm{w} / \mathrm{v})$ tryptone, $0.5 \%(\mathrm{w} / \mathrm{v})$ yeast extract) supplemented with $100 \mu \mathrm{g} / \mathrm{ml}$ ampicillin and $1 \%(\mathrm{w} / \mathrm{v})$ glucose. The culture was then incubated at $37^{\circ} \mathrm{C}$ until the absorbance at $600 \mathrm{~nm}$ was between $0.4-0.5$. VCSM13 helper phage was added to this culture and incubated for a further $30 \mathrm{~min}$ at $37^{\circ} \mathrm{C}$ without shaking. Cells were then centrifuged at $1500 \times \mathrm{g}$ for $10 \mathrm{~min}$. and the pellet resuspended in $2 \times \mathrm{TY}$ containing $100 \mu \mathrm{g} / \mathrm{ml}$ ampicillin and incubated with shaking at $30^{\circ} \mathrm{C}$ overnight. The overnight culture was centrifuged at $10,800 \times \mathrm{g}$ for $10 \mathrm{~min}$. and the pellet resuspended in $1 / 5$ volume of $20 \%(\mathrm{w} / \mathrm{v})$ polyethylene glycol 6000 in $2.5 \mathrm{M} \mathrm{NaCl}$ for $1 \mathrm{~h}$ at $4^{\circ} \mathrm{C}$. Phage particles were precipitated by centrifugation at $10,800 \times \mathrm{g}$ for $30 \mathrm{~min}$. then resuspended in $10 \mathrm{ml} \mathrm{H}{ }_{2} \mathrm{O}$ containing $20 \%$ (w/v) $\mathrm{PEG} / \mathrm{NaCl}$ and incubated for $20 \mathrm{~min}$. at $4{ }^{\circ} \mathrm{C}$. This solution was centrifuged at $3,300 \times \mathrm{g}$ for $30 \mathrm{~min}$. and the pellet containing phage particles was then resuspended in $2 \mathrm{ml} \mathrm{PAS} \mathrm{/} \mathrm{15 \%} \mathrm{(v/v)} \mathrm{glycerol.} \mathrm{Lastly,} \mathrm{the}$ supernatant, containing the phage was filtered through a $0.45 \mu \mathrm{m}$ filter and then stored at $-80^{\circ} \mathrm{C}$ prior to use. The bacteriophage titre was determined by serial dilution of infected $E$. coli plated out on TYE $(1.5 \%(\mathrm{w} / \mathrm{v})$ Bacto-agar $0.8 \%(w / v) ~ N a C l, 1 \%(w / v)$ tryptone and $5 \%(\mathrm{w} / \mathrm{v})$ yeast extract) supplemented with $25 \mu \mathrm{g} / \mathrm{ml}$ kanamycin. 


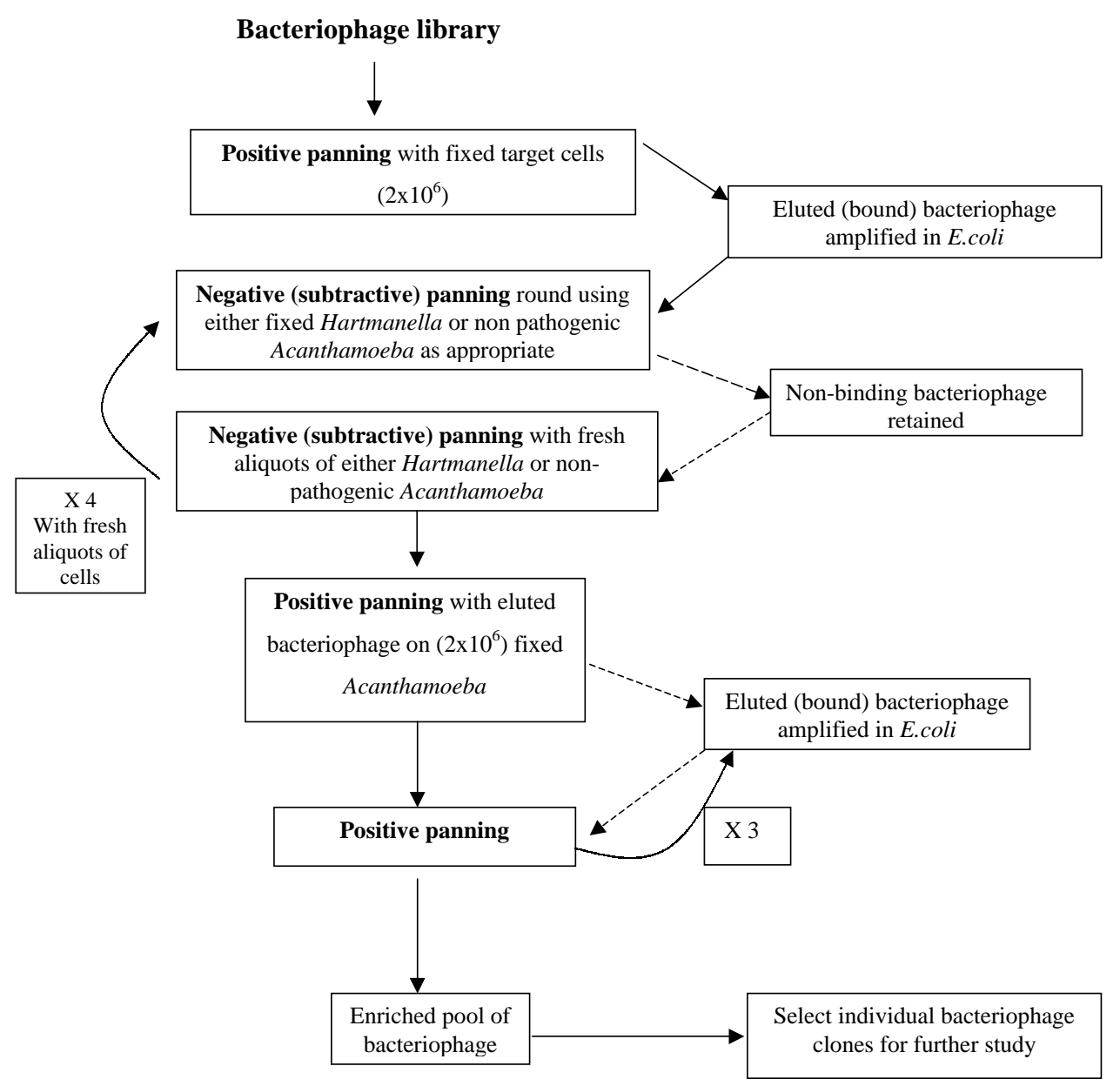

Fig. 1. Protocol for the isolation of Acanthamoeba specific bacteriophage clones.

\subsection{Use of phage antibody display library}

To isolate Acanthamoeba specific antibody fragments or those that can differentiate pathogenic isolates, an aliquot of the bacteriophage library (approx. $2 \times 10^{11}$ bacteriophage), was added to a suspension of whole fixed cells $\left(2 \times 10^{6}\right)$ which had been blocked by incubation in MPAS [2\% (w/v) dried milk powder, $1 \%(\mathrm{w} / \mathrm{v})$ bovine serum albumin in PAS] at $37^{\circ} \mathrm{C}$ for $1 \mathrm{~h}$. prior to use. The mixture of phage and cells was incubated at $20^{\circ} \mathrm{C}$ with gentle shaking for $1 \mathrm{~h}$. then centrifuged at $800 \times \mathrm{g}$ for $5 \mathrm{~min}$. The pellet was resuspended in $50 \mathrm{ml}$ of $0.1 \%(\mathrm{w} / \mathrm{v}) \mathrm{BSA}$ in PAS then centrifuged again; this process was performed 10 times in total to remove unbound phage. Citric acid (76 mM) was then added to the pellet and the suspension incubated at $20^{\circ} \mathrm{C}$ with shaking to remove bound phage from cells, the $\mathrm{pH}$ of the mixture was then adjusted to 7.0 by adding Tris- $\mathrm{HCl}(1 \mathrm{M}) \mathrm{pH}$ 7.4. This procedure was termed a panning round. The phage selected by this procedure were than amplified as described previously (see "Preparation of Bacteriophage Particles" above) except that bacteria infected with bacteriophage were spread onto TYE in a bio-assay dish and incubated at $30^{\circ} \mathrm{C}$ overnight. Overnight grown $E$. coli containing bacteriophage were scraped from the plate with $2 \times$ TY containing $15 \%(\mathrm{v} / \mathrm{v})$ glycerol and the suspension (library stock) was kept at $-70^{\circ} \mathrm{C}$ until required.

The protozoan, Hartmanella sp. was used for subtractive (negative) panning in the genus specific protocol; a pool of non-pathogenic species was used as the negative for the isolation of pathogen specific bacteriophage. Briefly, these cells were treated and blocked as described for target cells. The cells were then resuspended in MPAS and $2 \times 10^{11}$ phage (from the phage library isolated after one round of panning against the target organism) were added and incubated at $20^{\circ} \mathrm{C}$ with gentle shaking for $1 \mathrm{~h}$. Cells were centrifuged and 
(a)

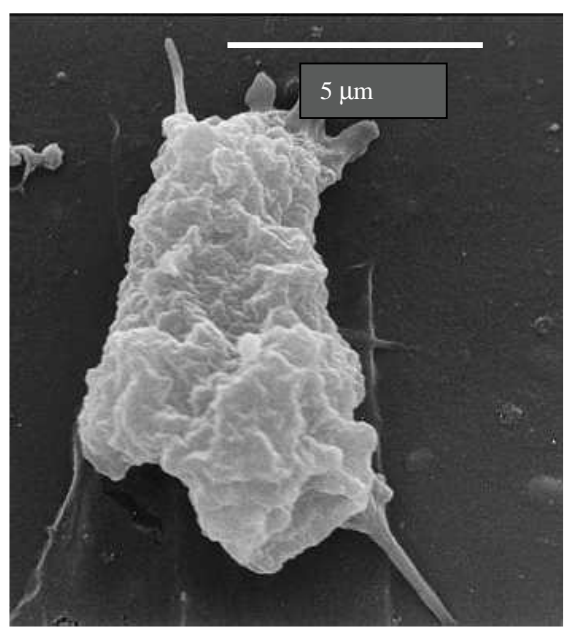

(b)

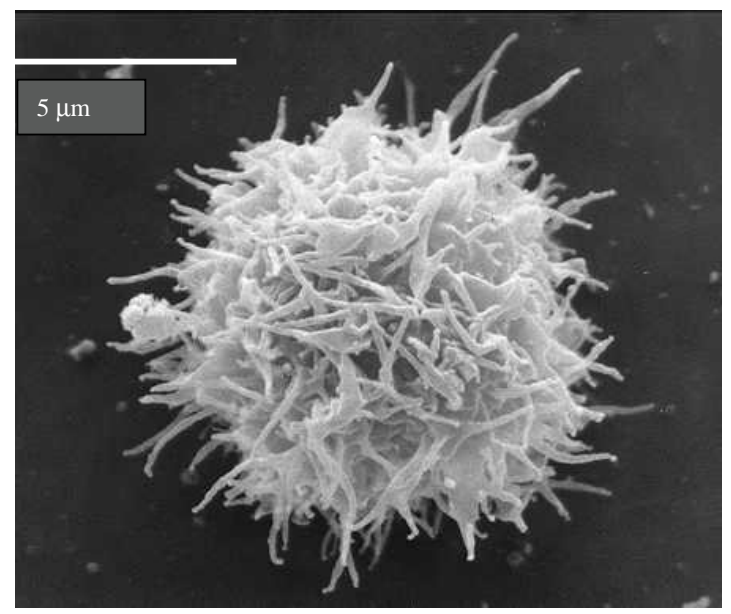

Fig. 2. SEM of Acanthamoeba spp. Species shown are (a) Acanthamoeba griffini and (b) A. castellanii.

supernatant containing unbound phage was incubated with a second aliquot of blocked cells. These were incubated with gentle shaking at $20^{\circ} \mathrm{C}$ for $30 \mathrm{~min}$. This procedure was repeated a further three times. Finally the supernatant containing unbound bacteriophage was incubated with fixed and blocked target cells and a positive panning round was performed. Two further rounds of positive panning were then performed. The complete panning procedure is shown in Fig. 1.

\section{6. $P C R$}

PCR was performed to demonstrate the diversity of phage clones isolated after each panning round $[13,14]$. PCR fragments were amplified directly from bacterial colonies using CDR-FOR (5' CAG GGT ACC TTG GCC CCA $3^{\prime}$ ) and CDR-BACK (5' GTG TAT TAC
TGT GCA AGA $3^{\prime}$ ) primers and were separated on $5 \%(\mathrm{w} / \mathrm{v})$ MetaPhor agarose gels (FMC Bioproducts, Flowgen).

\subsection{ELISA}

Single bacterial colonies were picked directly from the bioassay dish and inoculated into $2 \times$ TY supplemented with $100 \mu \mathrm{g} / \mathrm{ml}$ ampicillin $+1 \%$ (w/v) glucose and grown in 96 well round bottomed plates overnight at $37^{\circ} \mathrm{C}$. Glycerol stocks of the overnight incubations were made by adding $15 \%(\mathrm{w} / \mathrm{v})$ glycerol and stored at $-80^{\circ} \mathrm{C}$ until required. To rescue bacteriophage from glycerol stock cultures, 5-10 $\mu 1$ were transferred to a second round bottomed plate containing $2 \times \mathrm{TY}$ and incubated at $37^{\circ} \mathrm{C}$ for $1 \mathrm{~h}$. VCS-M13 helper bacteriophage $\left(1 \times 10^{9}\right)$ were added to each well and in- 
Table 2

The level and specificity of binding of bacteriophage clones to 7 species of Acanthamoeba and Hartmanella sp.

\begin{tabular}{lcccccccc}
\hline Clone designation & Sp1 & Sp2 & Sp3 & Sp4 & Sp5 & Sp8 & Sp9 & Hartmanella sp. \\
\hline HPPG 4 & + & ++ & ++ & ++ & + & ++ & ++ & - \\
HPPG 6 & ++ & ++ & ++ & ++ & ++ & ++ & ++ & - \\
HPPG 7 & + & ++ & + & ++ & ++ & + & ++ & - \\
HPPG 11 & ++ & ++ & ++ & + & + & ++ & ++ & - \\
HPPG 17 & ++ & + & ++ & ++ & ++ & ++ & + & - \\
HPPG 32 & ++ & + & + & ++ & ++ & + & ++ & - \\
HPPG 36 & ++ & + & ++ & + & ++ & ++ & + & - \\
HPPG 40 & ++ & + & ++ & + & ++ & ++ & ++ & - \\
HPPG 43 & ++ & + & ++ & ++ & ++ & + & + & - \\
\hline
\end{tabular}

Key: $(++)$ an absorbance at $405-690 \mathrm{~nm}>1.0 ;(+)$ indicates an absorbance $>0.5$ but $<1.0$; $(-)$ an absorbance $<0.1$. Species designations are given in Table 1 .

Table 3

Reactivity of clone HPPG6 as determined by fluorescent microscopy. A total of 7 Acanthamoeba spp. (environmental and clinical) were tested, all showed significant binding to HPPG6

\begin{tabular}{|c|c|}
\hline Organism & Reactivity \\
\hline Acanthamoeba palestinensis & + \\
\hline A. castellanii & + \\
\hline A. polyphaga & + \\
\hline A. astronyxis & + \\
\hline A. griffinii & + \\
\hline A.canthamoeba sp. 6 & + \\
\hline Acanthamoeba sp. 7 & + \\
\hline Hartmanella sp.* & - \\
\hline Candida albicans $^{*}$ & - \\
\hline Escherichia coli* & - \\
\hline Haemophilus influenzae* & - \\
\hline Nisseria sp. ${ }^{*}$ & - \\
\hline Pseudomonas aeruginosa* & - \\
\hline Klebsiella aerogenes* & - \\
\hline Monocytes** & - \\
\hline Lymphocytes** & - \\
\hline Neutrophils** & - \\
\hline
\end{tabular}

cubated for a further $30 \mathrm{~min}$. at $37^{\circ} \mathrm{C}$ without shaking, and then for $1 \mathrm{~h}$ with shaking. The plate was centrifuged at $400 \times \mathrm{g}$ for $10 \mathrm{~min}$, the supernatant aspirated, and the pellet resuspended in $2 \times$ TY supplemented with $50 \mu \mathrm{g} / \mathrm{ml}$ kanamycin and incubated overnight at $30^{\circ} \mathrm{C}$ with shaking (phage plate). The relevant fixed and blocked target cells $\left(2 \times 10^{5}\right)$ were added to the wells of a conical bottomed plate (Assay plates) and centrifuged at $200 \times \mathrm{g}$ for $5 \mathrm{~min}$. The supernatant was carefully removed and cells were washed with PAS. Phage plates grown overnight were centrifuged at $400 \times \mathrm{g}$ for $10 \mathrm{~min}$ and supernatant was used as a source of the bacteriophage. Bacteriophage particles were added to the assay plates and these were then incubated with shaking at $20^{\circ} \mathrm{C}$ for $1 \mathrm{~h}$ and then washed with PAS. Sheep anti M13-Horseradish peroxidase conjugate (Pharmacia, diluted 1:500 in blocking buffer) was added and incubated with shaking at $20^{\circ} \mathrm{C}$ for $1 \mathrm{~h}$. Cells were washed twice with PAS before 2,2azinobis(3-ethylbenzthiazoline sulfonic acid) (ABTS) substrate (Vector Laboratories) was added, and cells were transferred to a flat bottomed plate. The plate was then incubated at $20^{\circ} \mathrm{C}$ for $30 \mathrm{~min}$. in the dark before the supernatant was transferred to a flat-bottomed plate and the absorbance at 405-609 nm determined.

\subsection{Flow cytometry}

For flow cytometry, $10^{6}$ fixed and blocked target cells were mixed with $10^{12}$ phage from the appropriate clone and this was incubated at $4{ }^{\circ} \mathrm{C}$ for $1 \mathrm{~h}$. Cells were washed three times with $0.25 \%$ (w/v) bovine serum albumin, $0.04 \%(\mathrm{w} / \mathrm{v})$ Sodium azide in PAS (PAA) and resuspended in sheep anti-M13 antibody $(10 \mu \mathrm{g} / \mathrm{ml})$ and incubated at $4{ }^{\circ} \mathrm{C}$ for $1 \mathrm{~h}$. Cells were washed twice with PAA and resuspended in $50 \mu \mathrm{l}$ of fluorescein isothiocyanate-conjugated donkey anti-sheep immunogobulin $\mathrm{G}$ (IgG) (10 $\mu \mathrm{g} / \mathrm{ml}$, Vector Laboratories) and incubated at $4{ }^{\circ} \mathrm{C}$ for $1 \mathrm{~h}$. Cells were washed twice as above then resuspended in PAA and analysed by flow cytometry. Fluorescent activity was measured on a FACSCalibur and Cellquest software (Becton Dickinson) using an excitation wavelength of $488 \mathrm{~nm}$.

\section{Results}

\subsection{Scanning electron microscopy}

Scanning electron microscopy showed the presence of characteristic acanthopodia (Fig. 2). The nonpathogenic strains of Acanthamoeba tested have $<20$ acanthopodia while the pathogenic Acanthamoeba exhibited $>100$ acanthopodia per cell (Table 1). However, one species of non-pathogenic Acanthamoeba ( $A$. royreba), had $>100$ acanthopodia per cell. 
Table 4

The level and specificity of binding of bacteriophage clones to a range of pathogenic and non-pathogenic Acanthamoeba

\begin{tabular}{lccccccccc}
\hline Clone designation & \multicolumn{3}{c}{ Non pathogens } & & \multicolumn{3}{c}{ Pathogens } \\
\cline { 2 - 5 } \cline { 8 - 9 } & Sp1 & Sp2 & Sp3 & Sp5 & & Sp6 & Sp7 & Sp8 \\
\hline HPPG 52 & - & - & - & + & & + & + & + \\
HPPG 55 & - & - & - & - & & + & + & + \\
HPPG 56 & - & - & - & + & & + & + & - \\
HPPG 57 & - & - & - & - & & - & + & - \\
HPPG 67 & - & - & - & + & & + & + & - \\
HPPG 71 & - & - & - & - & & + & - & - \\
HPPG 74 & - & - & - & - & & - & + & + \\
HPPG 80 & - & - & - & - & & - & - & + \\
\hline
\end{tabular}

Key: (+) absorbance at 405-690 $\mathrm{nm}>0.5$; (-) absorbance equal to controls with irrelevant phage with. Species designations are given in Table 1 .

\subsection{ELISA}

Over 400 clones were analysed by ELISA from each of the two libraries in an attempt to isolate genus and pathogenic strain specificities. From the genus specific library, 10 clones with the highest binding to $A$. palestinensis (OD $\mathrm{A}_{405}-\mathrm{A}_{690}>0.8$ ) were selected initially. All showed high binding ( $>1.0$ absorbance units) to most or all of the Acanthamoeba spp. (Table 2). PCR analysis showed diversity within these clones (data not shown). Clone HPPG6 exhibited a high level of binding to all Acanthamoeba species, with no binding to a range of other cell types (Table 3 ). From the second "pathogenic" library, 8 clones were selected on the basis of ELISA reactivity using pooled pathogenic, and non-pathogenic Acanthamoeba. Only one clone (HPPG55) exhibited a useful binding profile (Table 4).

\subsection{Flow cytometry}

Flow cytometry showed strong binding of these antibody fragments against Acanthamoeba cells with no binding against other amoeba, bacterial strains or lymphocytes. Mean fluorescence for clone HPPG6 with A. palestinensis was 200 as compared with 48 for cells incubated with the irrelevant bacteriophage. No increase in fluorescence was seen with Hartmanella spp. (Fig. 3(c), (d)). This demonstrated the specificity of antibody fragments with Acanthamoeba spp. Clone HPPG55, isolated against pathogenic Acanthamoeba spp. showed mean channel fluorescence of 150 with $A$. castellanii as compared with 56 for cells incubated with irrelevant bacteriophage. No change in fluorescence was observed with A. astronyxis (Fig. 3(a), (b)).

\section{Discussion}

In this study we have shown that antibody fragments showing a high level of specificity for Acanthamoeba spp. can be isolated from a naive phage display library. This represents the first time that phage antibody display technology has been used in the development of a useful diagnostic antibody in microbiology. We were also able to isolate bacteriophage that can distinguish between pathogenic and non-pathogenic isolates cultured under various conditions.

Rabbit polyclonal antiserum has been used previously for detecting Acanthamoeba in corneal scrapings and in tissues of suspected meningoencephalitis, however these reagents showed considerable cross reactivity with other cell types and their sensitivity has been questioned [7]. Current methods for "rapid" identification of amoeba involve staining with Giemsa, calcofluor white, methylene blue or acridine orange. Accurate diagnosis and interpretation of results requires highly trained personnel together with a strong clinical suspicion of amoebic infection. A few groups have used the polymerase chain reaction as a rapid detection method for Acanthamoeba but its clinical use, specificity and sensitivity has not been tested [4]. With Acanthamoeba spp. becoming more important as causative agents for eye keratitis, due to increased contact lens use and meningoencephalitis in immunocompromised people, the need for a simple and rapid method for the specific detection is obvious.

To our knowledge the antibodies described above are the only demonstration of such an application on protozoan parasites, previous work has focussed on mammalian systems, e.g. tumours such as malignant melanoma [3]. Phage antibody display technique is a very useful and powerful tool for generating antibody fragments against a diverse array of molecules, many of 
(a)

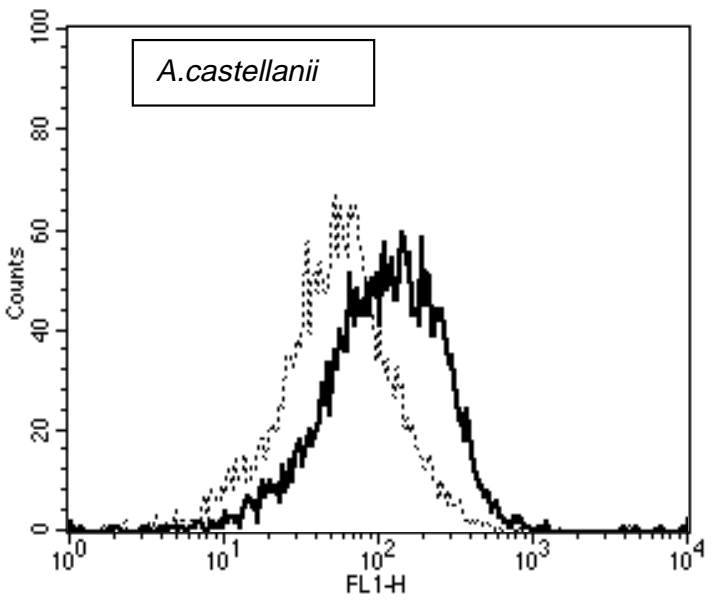

(b)

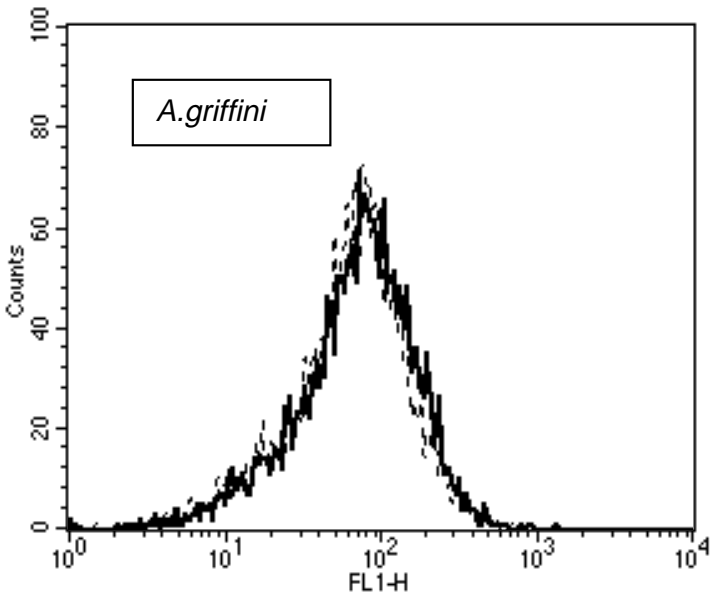

(c)

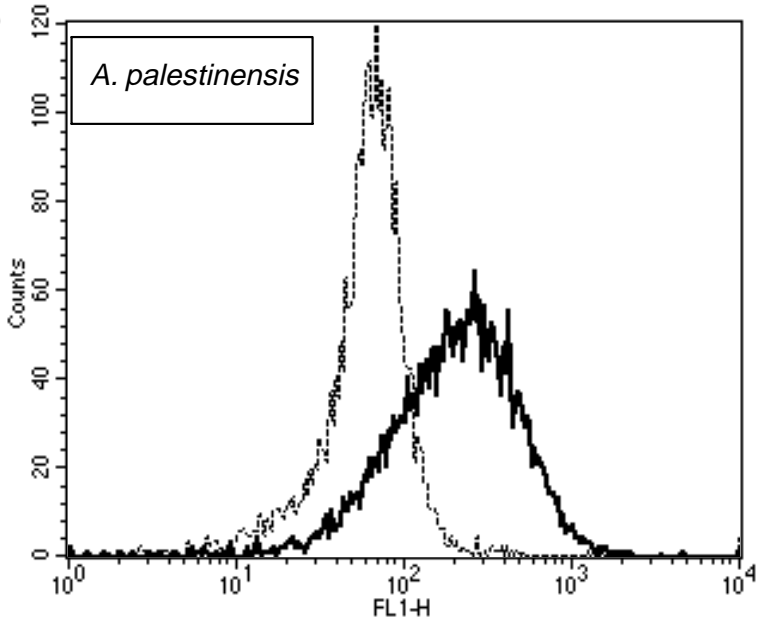

(d)

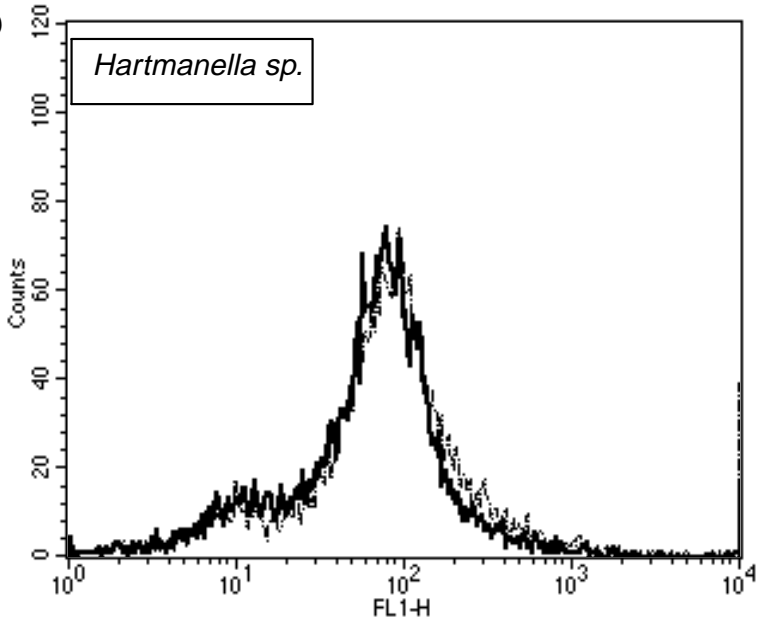

Fig. 3. Flow cytometry analysis of clone HPPG55 against A. castellanii (pathogenic) (a) and A. griffinii (non-pathogen) (b). The results of clone HPPG6, against A. palastinensis (c) and Hartmanella sp. (d). Parasites $\left(1 \times 10^{6}\right)$ were incubated with appropriate bacteriophage clone or irrelevant anti-NIP control $\left(1 \times 10^{12}\right)$ for 1 hour at $4^{\circ} \mathrm{C}$. Cells were then stained with a polyclonal sheep anti-M13 and fluorescein isothiocyanate donkey anti-sheep IgG. Samples were then analysed by flow cytometry. Irrelevant bacteriophage (- - -). Specific clone (-).

which can potentially be used in new diagnostic assays and perhaps chemotherapy.

Interestingly, using EM we also show that the number of acanthapodia is a marker for pathogenically, however our observation of significant numbers of acanthapodia on the non-pathogen $A$. royreba suggest that the relationship requires further verification using a larger number of species. Also, as acanthapodia are difficult to visualise using light microscopy, their use in routine identification is limited.

\subsection{Ongoing work}

We are currently expanding our work to look at two other protozoan parasites, Giardia intestinalis and
Cryptosporidium parvum. Our work on Giardia is discussed in another part of this supplement (Hough et al. "Isolation of anti-Giardia antibodies from a bacteriophage display library"). In addition, we are using bacteriophage to identify phenotypic characteristics that can differentiate the human infective and animal infective genotypes of C. parvum.

\section{References}

[1] D. Aitken, J. Hay, M.C. Kinnear and R.C. Lee, Amebic keratitis in a wearer of disposable contact lenses due to a mixed Vahlkampfia and Hartmannella infection, Ophthalmology 103 (1996), 485-494. 
[2] S.A. Bacon, K.G. John, A.L. Ficker, M.M. Matheson and P. Wright, Acanthamoeba keratitis, The value of early diagnosis, Ophthalmology 100 (1993), 1238-1243.

[3] X. Cai and A. Garren, Anti-melanoma antibodies from melanoma patients immunized with genetically modified autologous tumour cells: selection of specific antibodies from single-chain Fv fusion phage libraries, Proceedings of the $\mathrm{Na}$ tional Academy of Science USA 92 (1995), 6537-6541.

[4] W.E. Chynn, A.M. Lopez, P.D. Langston and H.J. Talamo, Acanthamoeba keratitis, Ophthalmology 102 (1995), 13691373.

[5] J.E.Cohen, W.H. Buchanan, A.P. Laughrea, P.C. Adams, G.P. Galentine, P. Folberg, J.J. Arentsen and R.P. Laibson, Diagnosis and management of Acanthamoeba keratitis, American Journal of Ophthalmology 100 (1985), 389-395.

[6] J.E. Cohen, C.J. Fultan, J.C. Hoffman, J.C. Rapuano and R.P. Laibson, Trends in contact lens-associated corneal ulcers, Cornea 15(6) (1996), 566-570.

[7] B.M. Flores, A.C. Garcia, E.W. Stamm and E.B. Torian, Differentiation of Naegleria fowleri from Acanthamoeba species by using monoclonal antibodies and flow cytometry, Journal of Clinical Microbiology 28(9) (1990), 1999-2005.

[8] L.S. Garcia, R.Y. Shimizu and C.N. Bernard, Detection of Giardia lamblia, Entamoeba histolytica / Entamoeba dispar and Cryptosporidium parvum antigens in human faecal specimens using the triage parasite panel enzyme immunoassay, Journal of Clinical Microbiology 38(9) (2000), 3337-3340.

[9] B.T. Grey, T.M. Ray, F. Sherwan and R.P. Rose, Acanthamoeba, bacterial and fungal contamination of contact lens storage cases, British Journal of Ophthalmology 79 (1995), 601-605.

[10] J.K. John, W. Steven, M.C. Parrish, E.T. Williams, D.R. Robinson and M. Denis, Examination of hydrophilic contact lenses with light microscopy to aid in the diagnosis of Acanthamoeba keratitis, American Journal of Ophthalmology 108(3) (1989), 329-331.

[11] N.A. Khan, J. Greenman, K.T. Topping, V.C. Hough, G.S. Temple and T.A. Paget, Isolation of Acanthamoeba-specific antibodies from a bacteriophage display library, Journal of Clinical Microbiology 38 (2000), 2374-2377.

[12] P. Ma, G.S. Visvesvara, A.J. Martinez, F.H. Theodore, P.M. Daggett and T.K. Sawyer, Naegleria and Acanthamoeba infections, Reviews of Infectious diseases 13(5) (1991), 369-372.

[13] J. Marks, H. Hoogenboom, Bonnert, J. McCafferty, A. Griffiths and G. Winter, Human antibodies from phage display libraries, Journal of Molecular Biology 222 (1991), 581.

[14] A. Nissim, R.H. Hoogenboom, M.I. Tomlinson, G. Flynn, C. Midgley, D. Lane and G. Winter, Antibody fragments from a 'single pot' phage display library as immunochemical reagents, EMBO Journal 13 (1994), 692.

[15] F.C. Page, A new key to the fresh water and soil gymnamoebae with instructions for culture, Freshwater Biological Association, Ferry House, Ambleside, Cumbria, UK, 1988.

[16] M.H. Vodkin, K.D. Howe, S.G. Visvesvara and L.G. Mclaughlin, Identification of Acanthamoeba at the generic and specific levels using the polymerase chain reaction, Journal of Protozoology 39 (1992), 378-385.

[17] K.R. Wilhelmus, The increasing importance of Acanthamoeba, Reviews of infectious Diseases 13(5) (1991), 367446.

[18] K. Winchester, D.W. Mathers, E.J. Sutphin and E.T. Daley, Diagnosis of Acanthamoeba keratitis in vivo with confocal microscopy, Cornea 14 (1995), 10-17.

[19] G. Winter, D.A. Griffiths, E.R. Hawkins and R.H. Hoogenboom, Making antibodies by phage display technology, Annual Reviews of Immunology 12 (1994), 433. 


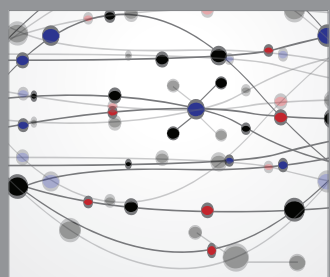

The Scientific World Journal
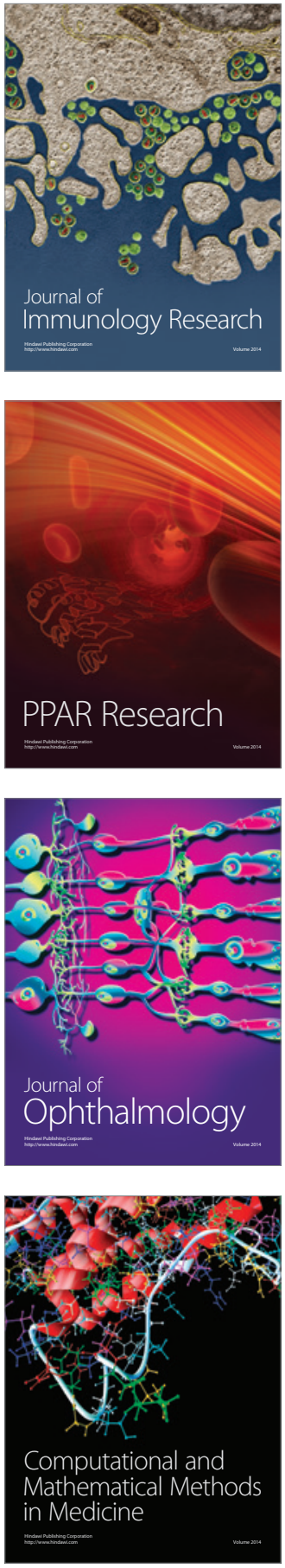

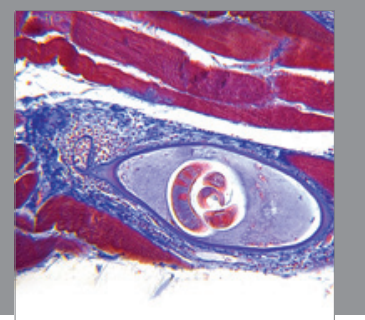

Gastroenterology

Research and Practice
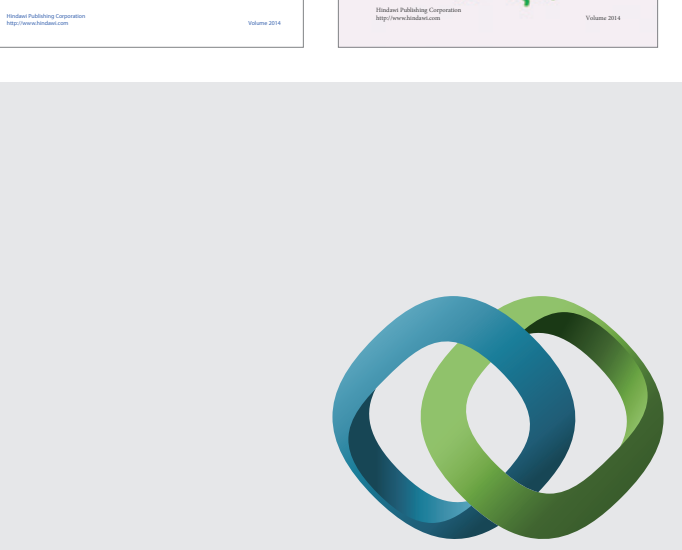

\section{Hindawi}

Submit your manuscripts at

http://www.hindawi.com
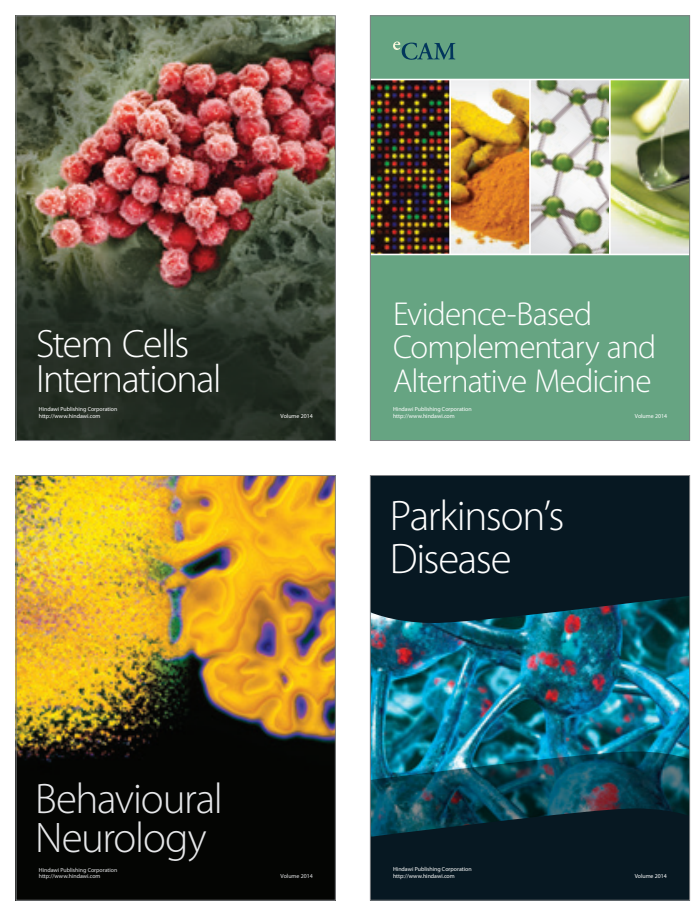

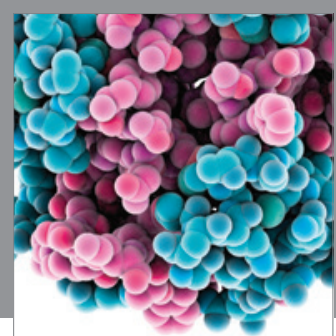

Journal of
Diabetes Research

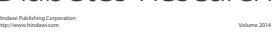

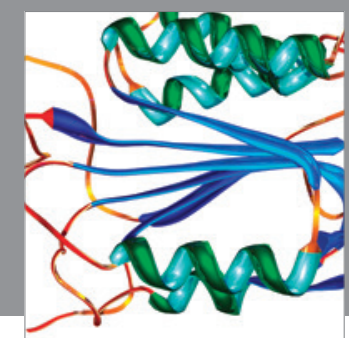

Disease Markers
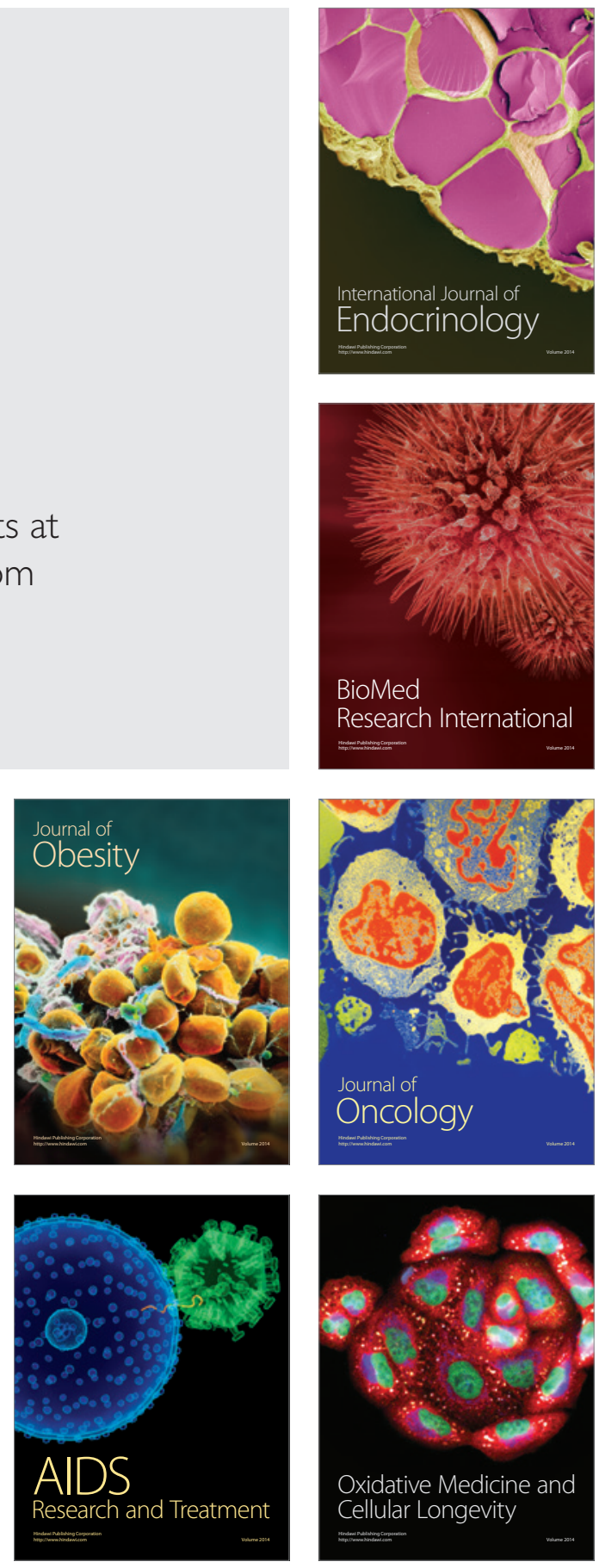